\title{
Analysis of critical length measurements for dry snow slab weak-layer shear fracture
}

\author{
D.M. MCCLUNG \\ Department of Geography, University of British Columbia, 1984 West Mall, Vancouver, British Columbia V6T 1Z2, Canada \\ E-mail: mcclung@geog.ubc.ca
}

\begin{abstract}
Snow slab avalanches primarily release by propagation of shear fractures within thin weak layers under much thicker slabs. In some cases, the weak layer is on the order of $\mathbf{1} \mathbf{~ m m}$ thick and such fractures may be considered to be a mode II shear fracture at initiation. In the cases analysed in this paper, the weak layer has finite thickness, and slope-normal effects may be present. Field data from $>500$ snow shear fracture tests are analysed and applied to the problem of weak-layer fracture. The paper contains a detailed analysis using a simple analytical model to estimate the critical length prior to an unstable shear fracture. The model contains the assumption of a finite fracture process zone which may be a significant fraction of the slab depth, $D$, or the critical length, $L$, for weak-layer shear fracture. The field results show that the $L / D$ ratio varies from $\sim 0.1$ to just over 2 , and the model results are close to the same range. The analysis also shows that both the field and model results for $L / D$ follow a Gumbel probability density function. Since the experimental field data contain rate-dependent (viscoelastic) and slope-normal effects, it is imperative to account for these in the model and for snow slab instability evaluation when using test data. Detailed evaluations considering both these effects are given. The applicability of the test data to avalanche release is discussed.
\end{abstract}

\section{NOTATION}

$D \quad$ Slab depth measured in slope-normal direction $(\mathrm{m})$

$d_{0} \quad$ Weak-layer thickness (m)

E Effective rate-dependent Young's modulus

$E^{\prime} \quad$ Effective rate-dependent modulus of snow slab (Pa)

$g \quad$ Magnitude of gravity acceleration: $9.81\left(\mathrm{~m} \mathrm{~s}^{-2}\right)$

$G_{\text {II }} \quad$ Mode II fracture energy $\left(\mathrm{J} \mathrm{m}^{-2}\right)$

$L \quad$ Critical length of shear fracture $(\mathrm{m})$

$L_{0} \quad$ Total length of snow block $(\mathrm{m})$

$p_{0} \quad$ One-dimensional depth-averaged longitudinal stress (pressure) (Pa) Longitudinal coordinate $(\mathrm{m})$

Slope-normal coordinate $(\mathrm{m})$

Displacement or slip along shear band $(\mathrm{m})$

Total slip along shear band $(\mathrm{m})$

Elastic shear modulus or viscoelastic modulus $(\mathrm{Pa})$

$\mu^{*} \quad$ Coefficient representing proportionality between slope-parallel traction and $\sigma_{\mathrm{N}}$ during rapid shearing

$\mu(f) \quad$ Frequency-dependent elastic shear modulus or viscoelastic modulus (Pa)

$\mu_{\mathrm{s}} \quad$ Shear modulus for slab

$\mu_{\mathrm{w}} \quad$ Shear modulus for weak layer

$\rho \quad$ Mean snow slab density $\left(\mathrm{kg} \mathrm{m}^{-3}\right)$

$\sigma_{\mathrm{N}} \quad$ Slope-normal stress on the weak layer (Pa)

$\tau_{\mathrm{r}} \quad$ Residual shear stress $(\mathrm{Pa})$

$v \quad$ Viscoelastic analog of Poisson's ratio

$\psi \quad$ Slope angle $\left(^{\circ}\right)$

$\omega \quad$ Length of fracture process zone $(\mathrm{m})$

\section{INTRODUCTION}

Dry snow slab avalanches are observed to release after mode II shear fracture propagation in a relatively thin weak layer under a thicker, planar slab. On average, the mode II fracture propagates within the weak layer for a distance on the order of $50 D$ (McClung, 2009a) prior to slab release, where $D$ is the slab depth measured in the slope-normal direction. It is natural to suppose that such weak-layer fractures also initiate as mode II fractures (Schweizer and others, 2003). Field tests resulting in shear fracture initiation in thin, weak layers under snow slabs, called propagation saw tests, were developed independently by Sigrist and Schweizer (Sigrist, 2006), Gauthier (2007) and Gauthier and Jamieson (2008). Models of the results of saw tests to predict the critical length, $L$, for slope-parallel shear fracture have also been developed (Heierli and others, 2008; McClung, 2009b).

One objective of the present paper is to explore the prediction of McClung's (2009b) model of the extensive measurements of the critical lengths, $L$, in the field tests, making use of the known mechanical and failure characteristics of alpine snow. These characteristics include ratedependent modulus (Mellor, 1975; McClung, 2007a), pressure sensitivity and strain-softening behaviour during shear failure and fracture (McClung, 1977, 1987; Schweizer, 1998), and finite fracture process zone (FPZ) during fracture (Sigrist and others, 2005; Sigrist, 2006; Borstad and McClung, 2009).

There are prominent slope-normal stress and pressure sensitivity effects implied by the field tests (McClung, $2009 b)$. In this paper, both rate effects and slope-normal effects are considered in comparison with the modelling results. The model used (McClung, 2009b) is based on the work of Cleary and Rice (1974) which is applicable when the fracture process zone length, $\omega$, may be as large as the critical length $(\omega / L \leq 1)$. The model contains the prediction of shorter critical length for higher applied normal stress which is evident in the field tests of Gauthier and Jamieson (2008) and of McClung.

Application of the model illustrates the complexity of modelling snow fracture using realistic assumptions 


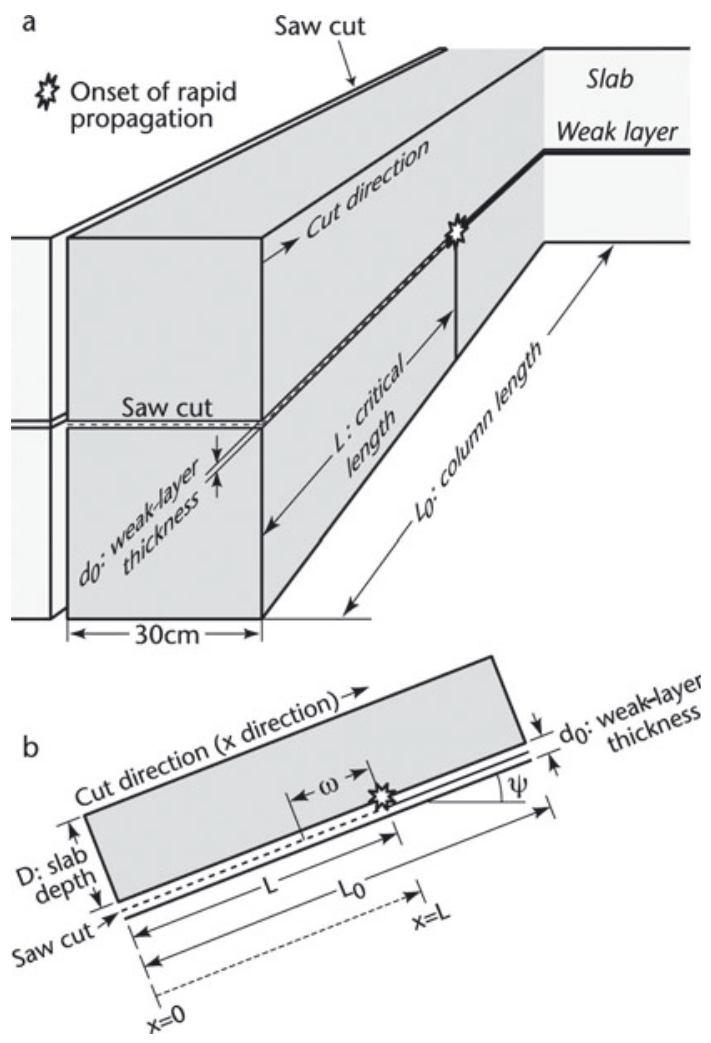

Fig. 1. (a) Schematic for field tests made with a saw cut of critical length $L$ within a weak layer of thickness $d_{0}$ with a total block length $L_{0}$. (b) Side-view schematic of the field tests, with $D$ as the slab depth and slope angle $\psi$. The parameter $\omega$ is the length of the fracture process zone. The coordinate system is defined such that $x$ is measured from the left end of the block $(x=0)$ to the end of the cut or slip surface $(x=L)$ in the direction of the dotted line in the centre of the weak layer.

regarding fracture and deformation properties. The verification results show that the model predictions of $L / D$ provide good estimates of the range, probability density function (PDF) and normal stress effects as seen in the data, even though the model is a simplified version of the deformation state in the tests.

Another objective of this paper is to relate applicability of the saw test results to avalanche release from field observations of both. The discussion of the test and avalanche observations reveals that applicability of the saw tests to avalanche applications must be made with caution.

\section{DESCRIPTION OF FIELD TESTS AND DATA CHARACTERISTICS}

The field tests are described in two subsections. Section 2.1 contains the basic description of performance of the tests. Section 2.2 contains descriptive aspects of the tests from high-speed films (300 frames $\mathrm{s}^{-1}$ ) and related observations of fractures during the tests.

\subsection{Performance of the tests}

Sigrist (2006), Gauthier (2007), Gauthier and Jamieson (2008) and McClung (2009b) provide detailed descriptions of the field tests used in this paper. Of the field test data, $>90 \%$ are from the work of Gauthier (2007) and Gauthier and Jamieson (2008). The procedure involves introducing a
Table 1. Descriptive statistics for $L, L / D, \rho, \psi$ and $D$ from 42 weaklayer/slab combinations comprising 559 tests. More than $90 \%$ of the data are from Gauthier (2007) and Gauthier and Jamieson (2008)

\begin{tabular}{lllccc}
\hline & & & \multicolumn{3}{c}{ Descriptor } \\
& $L$ & $L / D$ & $\rho$ & $\psi$ & $D$ \\
& $\mathrm{~m}$ & & $\mathrm{~kg} \mathrm{~m}^{-3}$ & $\circ$ & $\mathrm{m}$ \\
& & & & & \\
\hline Min. & 0.07 & 0.14 & 85 & 0 & 0.08 \\
Max. & 0.61 & 2.2 & 266 & 43 & 1.3 \\
Median & 0.29 & 0.88 & 164 & 30 & 0.33 \\
Mean & 0.30 & 0.98 & 165 & 27 & 0.39 \\
& & & & & \\
\hline
\end{tabular}

cut upslope or downslope within a weak layer underneath a long rectangular block of snow cut free on all sides. The cut is made to a critical length, $I$, at which the shear fracture propagates rapidly within the weak layer. Figure 1 contains a schematic of the test set-up. The block of snow is $30 \mathrm{~cm}$ wide with a total length $L_{0}=1 \mathrm{~m}$ and ideally more than two times $D$. In most of the tests, all sides are free surfaces.

The cut within the weak layer (Fig. 1) is made either upslope from the lower end of the block or downslope from the upper end of the block. Gauthier and Jamieson (2008) showed that there is no statistical difference between critical cut lengths made upslope or downslope. For the remainder of this paper and in the model presented later, I take the cut as being made upslope. With the cut starting from the free surface at the downslope end of the block, it is important that when the propagation condition is met, the cut is not close to the free surface at the upper end of the block. The standard length of the block is $1 \mathrm{~m}$ and median cut lengths do not exceed $0.65 \mathrm{~m}$, so this condition is normally fulfilled.

One important feature of the tests (Fig. 1) is that the weak layer must be thick enough so that the saw cut does not intersect the slab. Thus, the weak-layer thickness, $d_{0}$, should be greater than $\sim 5 \mathrm{~mm}$. The finite thickness of the weak layers tested, along with the finite thickness of the saw, gives rise to a two dimensional (2-D) deformation pattern in the weak layer with slow, slope-normal deformation working to bring the crack faces together. The 2-D aspect negates comparison of the test results with the earlier models (e.g. McClung, 1981) based strictly on slope-parallel deformation only in the weak layer. Avalanches sometimes release by shear fracture on weak layers which are on the order of $1 \mathrm{~mm}$ thick. Examples include layers of 2-D stellar crystals and surface hoar $\sim 1 \mathrm{~mm}$ thick. The analysis in this paper does not apply to these cases.

Table 1 contains descriptive statistics for field-measured parameters from 42 slab/weak-layer combinations compiled from 559 tests where $\rho$ is the mean slab density. All the tests were done on dry snow.

\subsection{Observations from high-speed films of the propagation saw tests}

When a saw cut is made within the weak layer, there are some important features which may not apply to avalanche release but are important in interpreting the test results. Highspeed films (300 frames $\mathrm{s}^{-1}$ ) and precision displacement, speed and acceleration estimates were made using particle tracking $\left(0.11 \mathrm{~mm} \mathrm{pixel}^{-1}\right)$ during the saw cuts. The particle tracking was done with particles attached to the slab. 
Maximum slope-normal displacement prior to propagation was $<1 \mathrm{~mm}$. Slope-parallel displacement in the slab was not observed. This is probably due to the resolution accuracy. In addition, the saw cut will produce the overwhelming amount of displacement in the weak layer, not the slab, and weaklayer displacements were not measured. Model predictions (section 7) suggest the total weak-layer slip, $\delta_{0}$, is on the order of a few tenths of a millimetre.

Two types of initial fractures are observed with the tests. In most cases, slope-parallel weak-layer propagation is observed. However, slab tensile fracture is sometimes observed, occurring at a distance of $\sim 1 D$ ahead of the saw. Gauthier (2007) presented extensive data from 87 slab/ weak-layer combinations representing $>800$ tests with a $2 \mathrm{~mm}$ thick saw. The data showed that in $16 \%$ of the combinations, tensile slab fracture was primarily observed in the individual tests; in $71 \%$, weak-layer propagation was primarily observed; and in 13\%, observations were missing or inconclusive or the mix of slab fractures and slopeparallel propagation was about the same. Thus, in most cases, the first fracture to propagate is in the slope-parallel direction which is interpreted here as mode II fracture.

The films and observations revealed that test results depend on the blade thickness of the saw used. With a thin saw $(1 \mathrm{~mm})$, the first fracture to propagate is nearly always in the slope-parallel direction. With a thicker saw $(3 \mathrm{~mm})$, the first fracture still usually propagates in the slope-parallel direction but tensile slab fractures occur more often than with the thin saw. For cases of tensile slab fracture, I believe that the gap created by the saw causes slab bending to precipitate the slab tensile fracture.

Tensile slab fractures in slab avalanches (McClung, 2009a) occur, on average, at a distance of $\sim 50 D$ after initiation, which is long after weak-layer propagation. Thus, the initial slab fractures seen in some of the propagation saw tests (at $1 D$ ) seem to be an artifact of a gap created by the saw rather than having much relation to avalanche tensile fractures.

In all cases, the films showed that the collapse mentioned in the models of Perla and LaChapelle (1970) and Heierli and others (2008) is a dynamic effect that occurs after, and in response to, the shock of either dynamic slope-parallel weak-layer propagation or dynamic tensile slab failure. Since the gap created by the saw is unlikely to be realistic for avalanche release, slope-parallel propagation, as seen in most of the tests, is assumed to be the initiation mechanism for fracture.

Results from high-speed films of the tests show there is very little contact of the faces of the crack behind the saw cut. Haefeli (1951, p.195; 1954, p.101-102) claimed to have measured the residual shear stress for alpine snow and $\tau_{\mathrm{r}} \approx 0$. Given these results, it is assumed that $\tau_{\mathrm{r}} \approx 0$ for the analysis in this paper. This assumption might not apply to avalanche initiation for which there is no saw cut.

\section{MODEL DESCRIPTION}

The model employed is derived by McClung (2009b). It is one-dimensional (1-D) even though the weak-layer deformation pattern produced by the saw is 2-D. Thus, it is a simplified version of what actually takes place when the saw cut is made.

The propagation condition for the geometry of Figure 1 is derived from the solution of two equations (equations 6 and
10) from McClung (2009b). These are given respectively as Equations (1) and (2) below for application to the tests with $\tau_{\mathrm{r}}=0$. Equation (1) relates driving energy to resistance to band motion:

$$
\frac{D p_{0}^{2}}{2 E^{\prime}}+\left(\mu^{*} \sigma_{\mathrm{N}}\right) \delta_{0}=G_{\|} .
$$

In Equation (1), the depth-averaged normal stress due to slab weight is $\sigma_{N}=\rho G D \cos \psi$ (with mean slab density $\rho$ ), $\mu^{*}$ is a dimensionless coefficient depending on weak-layer crystal form, $G_{\| I}$ is mode II weak-layer fracture energy, and $E^{\prime}=2 \mu /(1-v)$ is a rate-dependent effective modulus ( $\mu$ and $v$ are shear modulus and Poisson's ratio). In Equation (1), $-\rho_{0}$ is the depth-averaged longitudinal stress upslope and just beyond the end of the saw cut at $x=L$, and $\delta_{0}$ is total weaklayer slip at the free surface $(x=0)$ induced by the saw cut.

The other equation needed to complete the propagation condition (McClung, 2009b, equation 10) relates slip along the band to position $x$ :

$$
\begin{array}{r}
x=\frac{2}{C_{1}}\left[\sqrt{C_{0}-C_{1} \delta}-\sqrt{C_{0}-C_{1}(2 \bar{\delta})}\right]+L-\omega, \\
0 \leq x \leq L-\omega,
\end{array}
$$

where $C_{0}=2 G_{\mathrm{II}} / D E^{\prime}$ and $C_{1}=2\left(\mu^{*} \sigma_{\mathrm{N}}\right) / D E^{\prime}$. In Equation (2), $\delta(x)$ is slip at position $x$, and $\bar{\delta}$ is the mean value of slip inside the fracture process zone of length $\omega$.

With $\delta=\delta_{0}$ at $x=0$, Equations (1) and (2) may be combined to give the propagation condition which is solved for the critical length:

$$
\frac{L}{D}=\frac{1}{\mu^{*} \sigma_{\mathrm{N}}} \sqrt{\frac{2 E^{\prime} G_{\|}}{D}} \sqrt{1-\frac{2 \mu^{*} \sigma_{\mathrm{N}} \bar{\delta}}{G_{\|}}}+\frac{\omega}{D}-\frac{p_{0}}{\mu^{*} \sigma_{\mathrm{N}}} .
$$

Equation (3) contains five parameters $\left(E^{\prime}, G_{\| l}, 2 \bar{\delta}, \omega, \mu^{*}\right)$ that are not measured in the tests. The parameters are determined from measurements and estimates on alpine snow in section 4 to analyse the test results.

In Equation (3), the last two terms on the right are independent of $\sigma_{\mathrm{N}}$, since $p_{0}$ is proportional to $\sigma_{\mathrm{N}}$ (McClung, 1981). Of these two terms, the first, $\omega / D$, is small and positive and the second is small and negative. For the data comparison below, Equation (3) is approximated by assuming that these two terms (positive and negative) approximately cancel:

$$
\frac{L}{D}=\frac{1}{\mu^{*} \sigma_{\mathrm{N}}} \sqrt{\frac{2 E^{\prime} G_{\|}}{D}} \sqrt{1-\frac{2 \mu^{*} \sigma_{\mathrm{N}} \bar{\delta}}{G_{\|}}} .
$$

The assumption that the last two terms in Equation (3) can be neglected is partially justified by field tests below. Sigrist (2006, p. 68), from precision tensile tests on alpine snow, estimated that the FPZ for alpine snow is about $5-10 \mathrm{~cm}$ for the snow densities used in this paper. The median value of $D$ is $0.33 \mathrm{~m}$ for the tests, which gives an estimate of $\omega / D \approx 0.15-0.30$ as a rough average.

To evaluate the negative term, values of $\mu^{*}$ and $p_{0}$ are needed. For surface hoar (the most common weak layer in the tests), it is suggested in section 4 below that $\mu^{*}=0.2$. From McClung (1981), $p_{0}=[v / 2(1-v)] \sigma_{\mathrm{N}}$, where $v$ is interpreted as a viscoelastic analog of Poisson's ratio. Shinojima (1967) measured the ratio of lateral to compressive stress for viscoelastic compressive strain states for 35 snow samples (densities $90-275 \mathrm{~kg} \mathrm{~m}^{-3}$ ) to yield a mean value (0-0.1). Mellor (1975, p. 268) provides a broad range of suggested values for $v$, with the middle values matching 


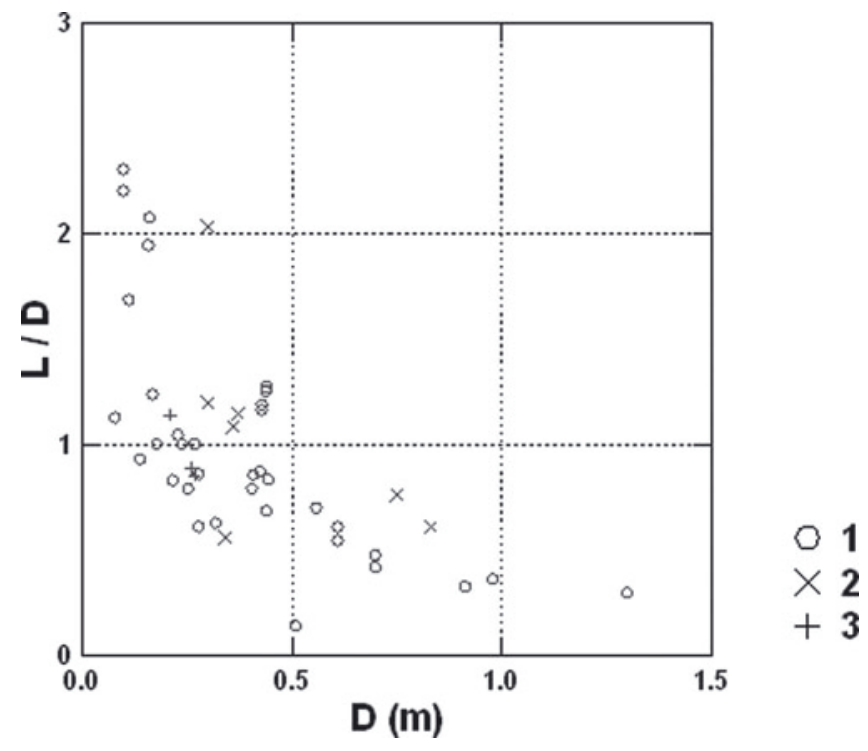

Fig. 2. Experimental values of $L / D$ versus $D$ for $45 \mathrm{slab} /$ weak-layer combinations representing 563 field tests. Numbers in the legend represent data sources: 1 (Gauthier, 2007; Gauthier and Jamieson, 2008); 2 (University of British Columbia); 3 (Sigrist, 2006).

the data of Shinojima (1967). Using the mean value $v=0.03$ (range 0-0.1), the last term in Equation (3) is $-p_{0} /\left(\mu^{*} \sigma_{N}\right) \approx 0.08$ for surface hoar with a range 0 to -0.28 using Shinojima's data.

The approximate estimates of the last two terms of Equation (3) suggest Equation (4) may provide slight underestimates, particularly for thin slabs. Figure 2 shows the field measurements for $L / D$ versus $D$ for 45 slab/weak-layer combinations (663 tests). The data show that low ratios of $L / D$ occur mostly for thicker slabs. Thus, the thinner slabs should not have significantly higher percentage error than the thicker slabs.

\section{MODEL INPUT PARAMETERS FROM PREVIOUS WORK}

Four of the input parameters $\left(2 \bar{\delta}, \mu^{*}, G_{\| I}, E^{\prime}\right)$ are taken from previous work since it is not possible to measure them along with the field tests. Each is described below in a separate subsection.

\subsection{Determination of $2 \bar{\delta}$ for snow in simple shear laboratory experiments}

Laboratory test results show that when failure is achieved during slow load application (a peak on a shear-stress/ displacement curve) alpine snow is in a dilatant state whether the sample simply fails and slowly softens after the peak, or fractures and collapses or settles rapidly after the peak is achieved (McClung, 2007c, 2009b. The laboratory results suggest that the characteristic mean displacement over which rapid softening takes place in a fracture experiment is of the order $2 \bar{\delta}=0.1 \mathrm{~mm}$. This value is similar to results in tension fracture experiments on alpine snow (McClung and Schaerer, 2006, p. 84; Sigrist, 2006; Borstad and McClung, 2009), and concrete (Bažant and Planas, 1998, p. 180). Slow shearing strain-softening failures on alpine snow without fracture typically show displacements over which softening takes place an order of magnitude above this value, i.e. $\bar{\delta}=1 \mathrm{~mm}$ or more (McClung, 1977; Schweizer, 1998; McClung and Schweizer, 1999).

The smaller displacement in shear during fracture, as opposed to slow softening, is of immense importance since the size of the FPZ is determined mostly by the material parameter $\bar{\delta}$ relatively independent of the size of the snow slab (Palmer and Rice, 1973). In the present study, the assumed value is $2 \bar{\delta}=0.08 \mathrm{~mm} \approx 0.1 \mathrm{~mm}$, which is an appropriate value for shear fracture experiments on dry snow during shear fracturing (McClung, 2009b). Precision estimates of $2 \bar{\delta}$ with closed loop testing in shear are not yet available for alpine snow.

\subsection{Determination of values of $\mu^{*}$ for weak-layer forms from field tests}

In the present model, the effective values of $\mu^{*}$ represent the pressure sensitivity for weak-layer forms by the proportion of slope-parallel traction accompanied by rapid slope-parallel weak-layer displacement as the saw cut is made. The traction is assumed to be the initial stress released by the saw cut. It is taken to be a fraction of the slope-normal stress at the weak layer: $\tau_{0}=\mu^{*} \sigma_{\mathrm{n}}$ (McClung, 2009b), which must be regarded as an approximation.

When a saw cut is made rapidly, as in the present experiments, fracture is rapid without the dilatant grain rearrangement during the slow laboratory shear tests. The values of $\mu^{*}$ applied in the model verification below were taken from pressure sensitivity tests on avalanche weak layers reported by Jamieson (1995), who placed weights on shear frames. The values were calculated by making linear fits through the shear frame strengths measured as a function of applied normal stress. These calculations gave the following values for $\mu^{*}$ for different crystal forms: 0.20 (surface hoar), 0.37 (facets), 0.07 (rounded facets) and 0.47 (decomposing and fragmented forms).

Independent confirmation of these values is provided by Van Herwijnen and Heierli (2009). They reported similar instantaneous, initial values just after failure but before frictional contact, which follows dynamic layer collapse. From experiments on surface hoar, faceted crystals and depth hoar from propagation saw tests, skier-tested events and rutschblock tests, reported values mostly range from about 0.2 to 0.4 , with one very low value of $\sim 0.02$. All these values are far below pressure sensitivity estimates from slow tests (McClung, 1987) which do not exhibit fast fracture.

Haefeli (1954, p. 116-119) reported similar experimental data on depth hoar. The tests were performed rapidly with duration of a few seconds since the rate of load application was $\sim 0.6 \mathrm{kPa} \mathrm{s}^{-1}$ and maximum shear strength was $\sim 2 \mathrm{kPa}$. A least-squares fit to the mean values of strength (mean value for five series of tests) with normal loads from 0 to $3 \mathrm{kPa}$ give a value $\mu^{*}=0.46$. Further refinement, taking into account changes in cohesion with normal stress according to Haefeli, gave $\mu^{*}$ in the range $0.27-0.36$. These results are in good agreement with the tests of Jamieson (1995) for the other persistent forms (surface hoar and facets) and the results of Van Herwijnen and Heierli (2009).

\subsection{Weak-layer mode II fracture energy, $G_{\text {II }}$}

In the present study, the weak-layer fracture energy is taken as a constant, median value estimated by McClung (2007c) for avalanche applications. The values (McClung, 2007c) were determined from slab avalanche fracture line data 
using the mode II stress intensity factor determined by Bažant and others (2003) assuming elastic slab behaviour. Due to the rate dependence of alpine snow, the present tests are too slow to be assumed elastic, so it would not be appropriate to determine $G_{\|}$along with the tests. The range of $G_{\| I}$ calculated from 278 slab avalanche profiles (McClung, 2007c) is $0.001-0.2 \mathrm{~J} \mathrm{~m}^{-2}$. The median value determined by McClung (2007a), $G_{\| I}=0.02 \mathrm{~J} \mathrm{~m}^{-2}$, is used in the present validation. This is comparable to, but lower than, values determined by Sigrist (2006) $\left(0.07 \mathrm{~J} \mathrm{~m}^{-2}\right)$ and Sigrist and Schweizer (2007) and assumed by Heierli and others (2008) $\left(0.03-0.07 \mathrm{~J} \mathrm{~m}^{-2}\right)$.

\subsection{Viscoelastic and rate-dependent modulus, $\boldsymbol{E}^{\prime}$}

Alpine snow is a highly rate-dependent material (Mellor, 1975; Chae, 1967; Shinojima, 1967) and it is required that deformation must be very rapid in order to avoid viscous effects. The experiments described in this paper have been performed with the speed of the saw cut on the order of $10-20 \mathrm{~cm} \mathrm{~s}^{-1}$ (Gauthier, 2007; McClung, 2009b), with time to fracture of several seconds. According to Palmer and Rice (1973), Rice (1973, p. 272) and Bažant (2005, p. 156), the slab modulus for viscoelastic deformation should be chosen in relation to the frequency implied by the speed of advance over the scale of the FPZ.

From the work of Sigrist (2006) and Borstad and McClung (2009), it may be inferred that the scale of the FPZ in rapid tension fractures is about $5-10 \mathrm{~cm}$, which is similar to the saw width in the present work. Such estimates are for slab material with, normally, smaller grain sizes than for weaklayer forms. Thus, it is possible that, on average, the FPZ for the weak layers used in this paper (mostly surface hoar) may be larger than $5-10 \mathrm{~cm}$. For application of the saw tests to shear fractures, the speed of advance relative to the FPZ size implies that the relevant frequency is of order $1 \mathrm{~Hz}$ for choice of the modulus.

For this paper, the viscoelastic storage shear modulus of the slab, $\mu_{\mathrm{s}}$, at a frequency of $1 \mathrm{~Hz}$ as a function of mean slab density, $\rho\left(\mathrm{kg} \mathrm{m}^{-2}\right)$, is determined by a nonlinear fit through the data of Camponovo and Schweizer (2001) from McClung (2007a) as:

$$
\log _{10}\left(\mu_{\mathrm{s}}\right)=5.58+0.00857(\rho-215) ; \mu_{\mathrm{s}}(\mathrm{Pa}), 1 \mathrm{~Hz} \text {. }
$$

The field data are all taken from weak layers with finite thickness $d_{0}$, on average, $\sim 2 \mathrm{~cm}$. For a layered system, it is shown by Hutchinson and Suo (1992) that the effective shear modulus, $\mu$, for describing fracture varies between $\mu_{\mathrm{wl}}<\mu<\mu_{\mathrm{s}}$, where $\mu_{\mathrm{wl}}$ is the effective modulus for the weak layer. The upper limit, $\mu_{\mathrm{s}}$, applies for an infinitesimally thin crack adjacent to the slab, and the lower limit, $\mu_{\mathrm{wl}}$, applies for a thin crack entirely embedded within a thick weak layer. For the present experiments, the weak layer is thin, but of finite thickness, and the saw cut is not infinitesimally thin. so the effective modulus should be between the limits. From hardness differences between the slab and weak layer, it is suggested that the weak layer is typically lower by a factor of 10 or more in modulus than the slab in avalanche work. Thus, it is possible that the appropriate modulus, $\mu$, to describe the fracture may vary from the slab stiffness to a factor of ten or so lower than the slab stiffness.

For the present paper, the shear modulus is assumed to vary as with a constant stress model from Hull and Clyne (1996) for a composite material. For a slab with a weak layer occupying a fraction, $f$, of the slab/weak-layer system, mixture theory gives the effective shear modulus as

$$
\mu=\left(\frac{f}{\mu_{\mathrm{wl}}}+\frac{1-f}{\mu_{\mathrm{s}}}\right)^{-1},
$$

where $f=d_{0} / D, \mu_{\mathrm{wl}}$ is the effective modulus of the weak layer and $d_{0}=0.02 \mathrm{~m}$ is the average weak-layer thickness. It is assumed that the weak layer has a modulus of $\mu_{\mathrm{wl}}=$ $(1 / 20) \mu_{\mathrm{s}}$ in the model calculations below. This assumption produces an effective modulus appropriate for the experiments of, on average, about half $\mu_{\mathrm{s}}$ appropriate for the slab of given average density. For a median value of $D$, $f=d_{0} / D=0.02 \mathrm{~m} / 0.33 \mathrm{~m}=0.06$ and slab modulus 20 times the weak-layer modulus, Equation (6) yields $\mu=\mu_{\mathrm{s}} / 2.14$.

The constant stress mixture model contained in Equations (5) and (6) yields the limits predicted by Hutchinson and Suo (1992) for the special cases they considered. If $d_{0} / D \rightarrow 0$ then $\mu \rightarrow \mu_{\mathrm{s}}$, for the case in which an infini tesimally thin crack is adjacent to the slab. If $d_{0} / D \rightarrow 1$, then $\mu \rightarrow \mu_{\mathrm{wl}}$ for the case in which an infinitesimally thin crack is entirely within a weak layer. The high-speed films (300 frames $\mathrm{s}^{-1}$ ) of the tests and the work of Sigrist (2006, p. 90) have shown that the slope-normal deformation within the saw cut is not infinitesimal as assumed in the linear elastic fracture mechanics (LEFM) model of Hutchinson and Suo (1992). Nevertheless, their work suggests reasonable bounds on the effective modulus. Of the two bounds, $\mu \rightarrow \mu_{\mathrm{s}}$ is the most unrealistic, since the crack is neither infinitesimally thin, nor directly adjacent to the slab. In order to perform the tests, so that the saw cut does not enter into the slab, the layer thickness must be greater than about $d_{0}=5 \mathrm{~mm}$ such that the saw cut remains entirely within the weak layer.

The effective modulus used in this paper for mode II fracture is

$$
E^{\prime}=2 \mu /(1-v),
$$

where $v$ is the analog Poisson's ratio for viscoelastic correspondence. For the low-density snow in the experiments (85-266 $\mathrm{kg} \mathrm{m}^{-3}$ ), based on results suggested by Mellor (1975) and summarized by Salm (1977), it is assumed that $v=0.1$. This corresponds to the upper limit of the data of Shinojima (1967).

Equation (7) represents an important assumption in the analysis below. It is partially justified by the model success explained below and the fact that the effective modulus for the layered system (slab/weak-layer) should be less than that for the slab for weak layers of finite thickness, as with the experiments. In the experiments, the saw is forced through the weak layer and energy transfer takes place both in the slab and weak layer.

\section{ESTIMATES OF L/D FROM THE 1-D MODEL}

\subsection{Direct model comparison with data}

Table 2 contains a summary of input parameters used in the model comparison for the four input parameters not measured in the tests. The parameter $E=2 \mu(1+v)=2.2 \mu$ is the implied rate-dependent Young's modulus, which may easily be compared with published values (Schulson and Duval, 2009).

Figure 3 shows comparison of the data for 27 weak-layer/ slab combinations (355 tests) for which the weak-layer crystal 


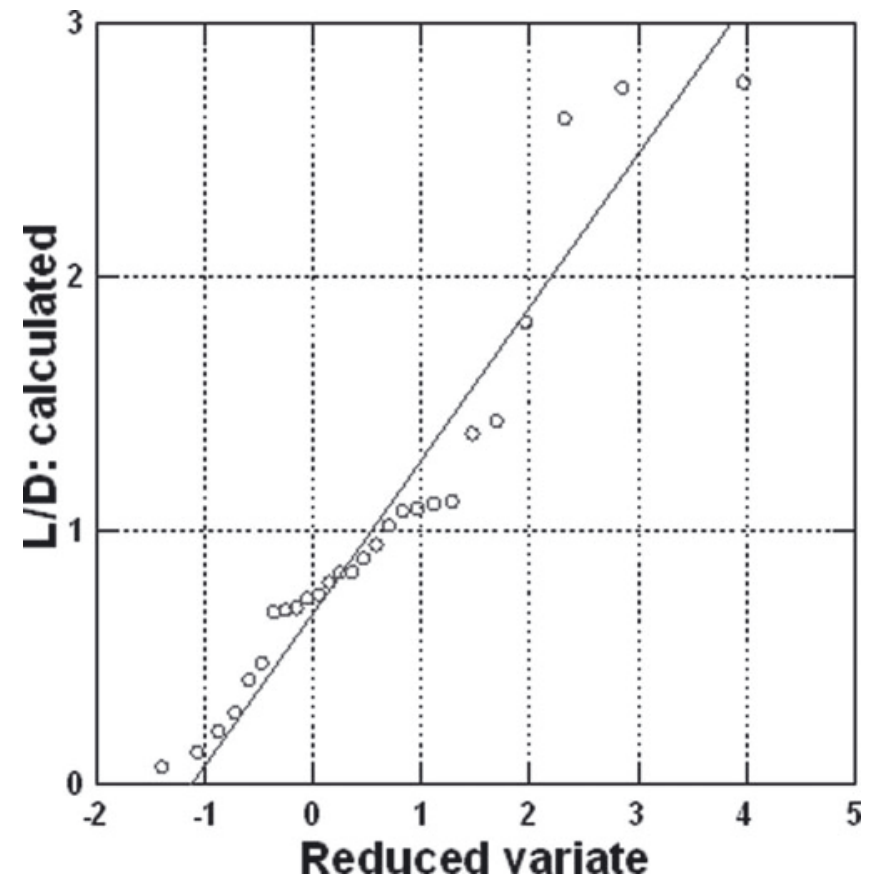

Fig. 3. Scatter plot of calculated versus measured values of $L / D$ for 27 slab/weak-layer combinations representing 355 tests. The constant of proportionality is within $95 \%$ confidence limits.

forms are known. Nonlinear regression modelling showed

$$
(L / D)_{\text {calc }}=C(L / D)_{\text {meas }}
$$

where $C=1.01 \pm 0.13$ within $95 \%$ confidence limits and percentage variance explained as $R^{2}$ (Predicted/Observed) $=$ 0.76. There is considerable scatter in Figure 3. This is partly due to natural variations in the data with two input parameters $\left(\bar{\delta}, G_{\| I}\right)$ left constant.

\subsection{Implied probability density function}

Figure 4 shows the experimental data for $L / D$ fitted to a Gumbel PDF. The data represent 45 different weak-layer/ slab combinations and 563 tests. The abscissa is the Reduced Variate defined as $-\ln \left(-\ln \left(P_{N}\right)\right.$, where $P_{N}$ is the non-excedance probability given by $P_{\mathrm{N}}(x)=\int_{-\infty}^{x} f_{X}\left(x^{\prime}\right) \mathrm{d} x^{\prime}$ and $f_{X}(x)(x=L / D)$ is the PDF. A Kolmogorov-Smirnov (KS) goodness-of-fit test gave the K-S test statistic as 0.103 with a $p$ value of 0.721 . The location parameter and scale parameters are 0.76 and 0.39 respectively.

Figure 5 shows calculated model values for 27 weaklayer-slab combinations (355 tests) fitted to a Gumbel PDF using the parameters above. The K-S statistic is 0.155 with a $p$ value of 0.533 . The location parameter is 0.70 and the scale parameter is 0.56 .

Table 2. Values of the four input parameters used in the model comparison

\begin{tabular}{lcc}
\hline Parameter & Value & Comment \\
\hline$G_{\mathrm{II}}$ & $0.02 \mathrm{~J} \mathrm{~m}^{-2}$ & Kept constant \\
$2 \bar{\delta}$ & $0.08 \mathrm{~mm}$ & Kept constant \\
$E$ & $0.1-3.4 \mathrm{MPa}$ & Varied with $\rho\left(85-266 \mathrm{~kg} \mathrm{~m}^{-3}\right)$ \\
$\mu^{*}$ & $0.07-0.47$ & Varied with weak-layer form \\
\hline
\end{tabular}

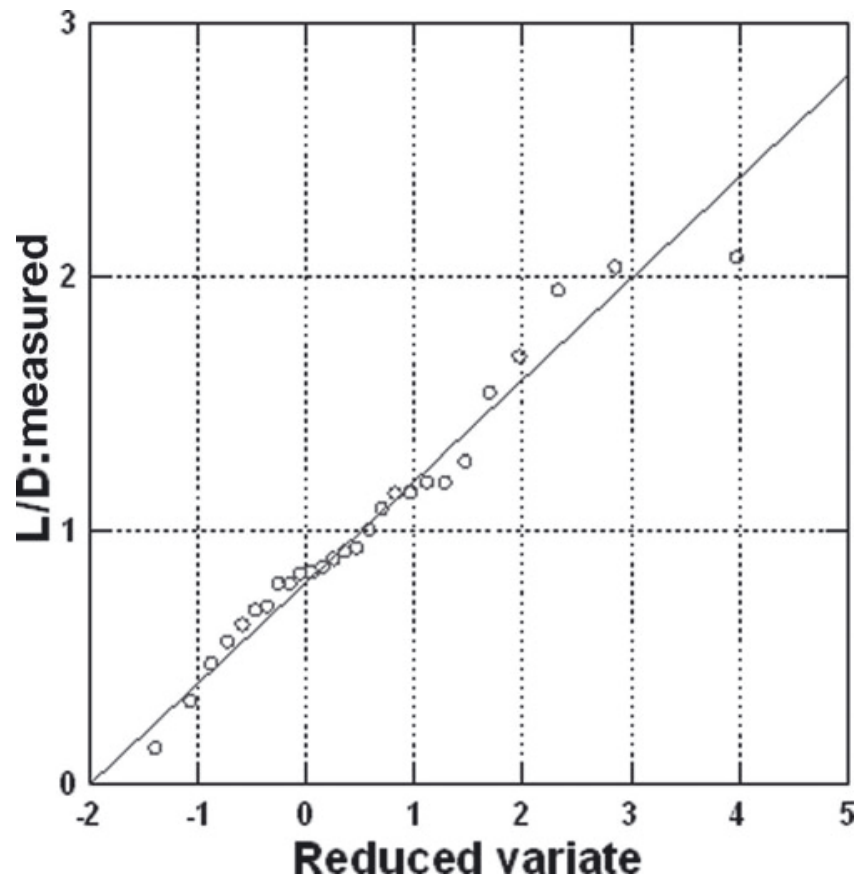

Fig. 4. Probability plot for experimental values of medians for 45 slab/weak-layer combinations, weak layers representing 563 tests. The plot suggests that the ratio follows a Gumbel normal PDF. The reduced variate is $-\ln \left(-\ln \left(P_{N}\right)\right)$, where $P_{N}$ is the non-exceedance probability defined in the text.

Other distributions were considered including lognormal, Weibull, Frêchet and gamma, but the Gumbel PDF was chosen since it gave the best goodness-of-fit statistics and the best fit for the probability plot for both the sets of measured and calculated values. Thus, the choice of the Gumbel PDF is empirically based.

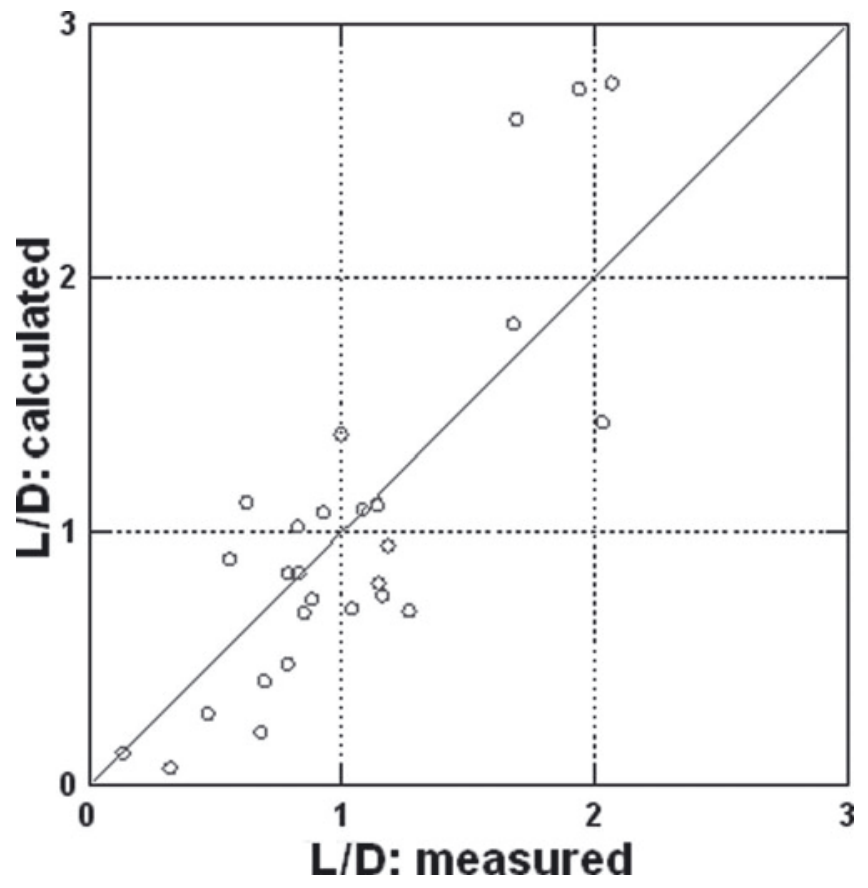

Fig. 5. Probability plot for 27 slab/weak-layer combinations representing calculated vales for 355 tests similar to Figure 3 . The plot suggests the values follow a Gumbel probability function. 
Due to lack of information about slab density, weak-layer crystal form or $\mu^{*}$, Figure 5 does not have as many weaklayer/slab combinations as Figure 4. The constant input parameters, $\left(G_{\| I}=0.02 \mathrm{~J} \mathrm{~m}^{-2} ; 2 \bar{\delta}=0.08 \mathrm{~mm}\right)$ imply $\mu^{*} \sigma_{N}<250 \mathrm{~Pa}$ in order to obtain a solution. Thus, some slab/weak-layer combinations did not yield solutions for high normal stresses $(>1 \mathrm{kPa})$. The highest slope-normal stresses in the database come from faceted weak layers with slope-normal stress around $2500 \mathrm{~Pa}$, which either implies $\mu^{*}<0.1$ or $G_{\| I}>0.02 \mathrm{~J} \mathrm{~m}^{-2}$.

Both of these explanations are possible. Jamieson (1995) measured a weak layer with rounded, faceted forms which implies $\mu^{*}=0.07$ so the model can still apply. Importantly, high slope-normal stresses are usually associated with weak layers of older snow which may have higher fracture energy values than the average used in the model comparison here. It is well known that the shear strength of weak layers tends to increase with normal stress overburden and time, provided they are not subject to high temperature gradients (Chalmers and Jamieson, 2003; Zeidler and Jamieson, 2006). Since shear strength is an important component of $G_{\|}$(Bažant and others, 2003), it is expected that $G_{\|}$ increases as layers age and $\sigma_{N}$ increases by snow loading. In deep alpine snowpacks, strong temperature gradients are usually found in the upper portion, not at deep weak layers.

Use of $G_{\| I}=0.1 \mathrm{~J} \mathrm{~m}^{-2}$ yields predictions for any case in the database. Assuming $G_{\|}=0.1 \mathrm{Jm}^{-2}$ for two deep slabs (highest values of $\sigma_{N}$ in the database) on a faceted layer (Gauthier and Jamieson, 2008) gave L/D (measured; predicted) as: $(0.29 ; 0.25)$ and $(0.36 ; 0.55)$ for values of $(D, \rho, \psi)$ respectively of: $\left(1.3 \mathrm{~m} ; 233 \mathrm{~kg} \mathrm{~m}^{-3} ; 23^{\circ}\right)$; $(0.98 \mathrm{~m}$; $262 \mathrm{~kg} \mathrm{~m}^{-3} ; 0^{\circ}$ ).

\subsection{General slope-normal dependence}

Slope-normal dependence in the field data and the model is a direct consequence of the release of gravitational potential energy by making the saw cut in a relatively thick weak layer. In order to isolate one parameter in field tests, slopenormal dependence in this case, the slab and weak layer properties must be roughly the same for each slope angle.

Three datasets are available for testing slope-normal dependence: (1) tests on slopes of $0^{\circ}, 30^{\circ}$ and $38^{\circ}$ reported by Gauthier and Jamieson (2008) for a weak layer of decomposing and fragmented crystals (DF); (2) tests on a surface hoar (SH) layer at Rogers Pass, British Columbia, Canada (McClung, 2009b); and (3) tests on a surface hoar $(\mathrm{SH})$ layer at Kootenay Pass, British Columbia (McClung, 2009b). Table 2 contains a summary of test results in comparison with the model. The results show that the model predicts the correct trend and magnitude. For the same slab and weak layer, critical length increases with slope angle.

For constant slope angle $\left(\psi=30^{\circ}\right)$, three sets of measurements with a weak layer of faceted snow reported by Sigrist (2006) gave the following results for pairs of $L / D$ (measured; predicted): (0.85; 0.67); (0.89; 0.73); (1.14; 1.10).

In order to explore the general slope-normal dependence further, Equation (4) may be expressed as

$$
\frac{L}{D}=\frac{C_{1}}{\sigma_{\mathrm{N}}} \sqrt{1-C_{2} \sigma_{\mathrm{N}}}
$$

where $C_{1}=\left(1 / \mu^{*}\right) \sqrt{2 E^{\prime} G_{\| I} / D}$ and $C_{2}=\left(2 \mu^{*} \bar{\delta} / G_{\|}\right)$. Theoretical calculations of $C_{1}$ for 35 slab/weak-layer calculations, with the inputs described above, show that it varies from 115 to $992 \mathrm{~Pa}$, with a median value of $540 \mathrm{~Pa}$. In order that the calculations may extend over the entire range of slope-normal stresses in the data (maximum value $2735 \mathrm{~Pa}$; faceted snow), it is assumed that $u^{*}=0.07$ (minimum value for faceted weak layer) in $C_{2}$ to give an estimate $\mathrm{C}_{2}=0.28 \times 10^{-3}\left(\mathrm{~Pa}^{-1}\right)$ with $2 \bar{\delta}=0.08 \mathrm{~mm}, G_{\| I}=0.02 \mathrm{~J} \mathrm{~m}^{-2}$ as before. The normal stress calculations show that there is a lack of data between $\sigma_{\mathrm{N}}=1-2 \mathrm{kPa}$, but the data suggest rapid decline in the value of $L / D$ up until $\sim 1 \mathrm{kPa}$ normal stress, and the model predicts similar behaviour.

Nonlinear robust regression of the data for Equation (9) (42 slab/weak-layer combinations), using the Marquardt algorithm with $C_{2}=0.28 \times 10^{-3} \mathrm{~Pa}^{-1}$, gave a value $C_{1}=293 \mathrm{~Pa}$ that falls approximately midway between the minimum (115 Pa) and median (540 Pa) values estimated theoretically. The percent variance explained for the nonlinear regression is (raw) $R^{2}=0.77$. Figure 6 shows three calculated curves based on the theoretical minimum, maximum and median values of $C_{1}$ compared with the measured data versus normal stress calculated from the data. The results show that the theoretical curves bracket the measurements well and the median curve goes approximately through the middle range of most of the data.

These numerical results are not sensitive to the chosen value of $C_{2}$. If $C_{2}=0$ then $C_{1}=286 \mathrm{~Pa}$ and if $C_{2}=0.36 \times$ $10^{-3} \mathrm{~Pa}^{-1}$ then $C_{1}=295 \mathrm{~Pa}$. The latter value of $C_{2}$ is the largest allowable for the dataset given that the highest value of $\sigma_{\mathrm{N}}$ is $2.375 \mathrm{kPa}$ so that the constraint on Equation (4) is satisfied. The reason the calculations are not sensitive to $C_{2}$ is the scarcity of data for $\sigma_{\mathrm{N}}$ between 1 and $2 \mathrm{kPa}$.

\section{RELATION TO AVALANCHE RELEASE AND FORECASTING}

It is important that the results of the propagation saw tests be used carefully when applied to slab avalanche initiation. Two very important differences are evident from observations during the tests.

First, introduction of a saw cut produces a gap behind the saw which depends importantly on the thickness of the saw used. In the case of slab avalanche release, there is no such gap (Schweizer and others, 2003). The tensile slab fractures in the tests are caused by the artificial gap produced by the saw to produce bending at a distance of $\sim 1 D$ ahead of the saw. The tensile fracture at the crowns of slab avalanches occurs, on average (McClung, 2009a), a distance of $\sim 50 D$ upslope of the weak-layer fracture initiation point. This suggests that the separation gap introduced by the saw cut, and the slab bending associated with it, does not play a role in tensile fracture of the crown of avalanches. If slab bending effects in avalanche initiation were comparable to those produced by the saw gap, one would expect to see slab avalanche tensile fractures at short distances.

Second, direct extrapolation of results of the saw tests, where a gap is made with the saw, to avalanche release where the deformation conditions are not well known, must be carefully done. The interest in the propagation saw tests is that they exhibit slope-parallel weak-layer propagation even if $\psi=0^{\circ}$, which is a characteristic of natural weak-layer propagation under human influences. The most likely reason either saw tests or natural fractures can produce propagation for $\psi>0^{\circ}$ is that both induce complex loading with slopenormal and slope-parallel weak-layer deformation. Natural propagation for low slope angles or $\psi=0^{\circ}$ is not observed for slow loading by snowfall which is the most common cause 


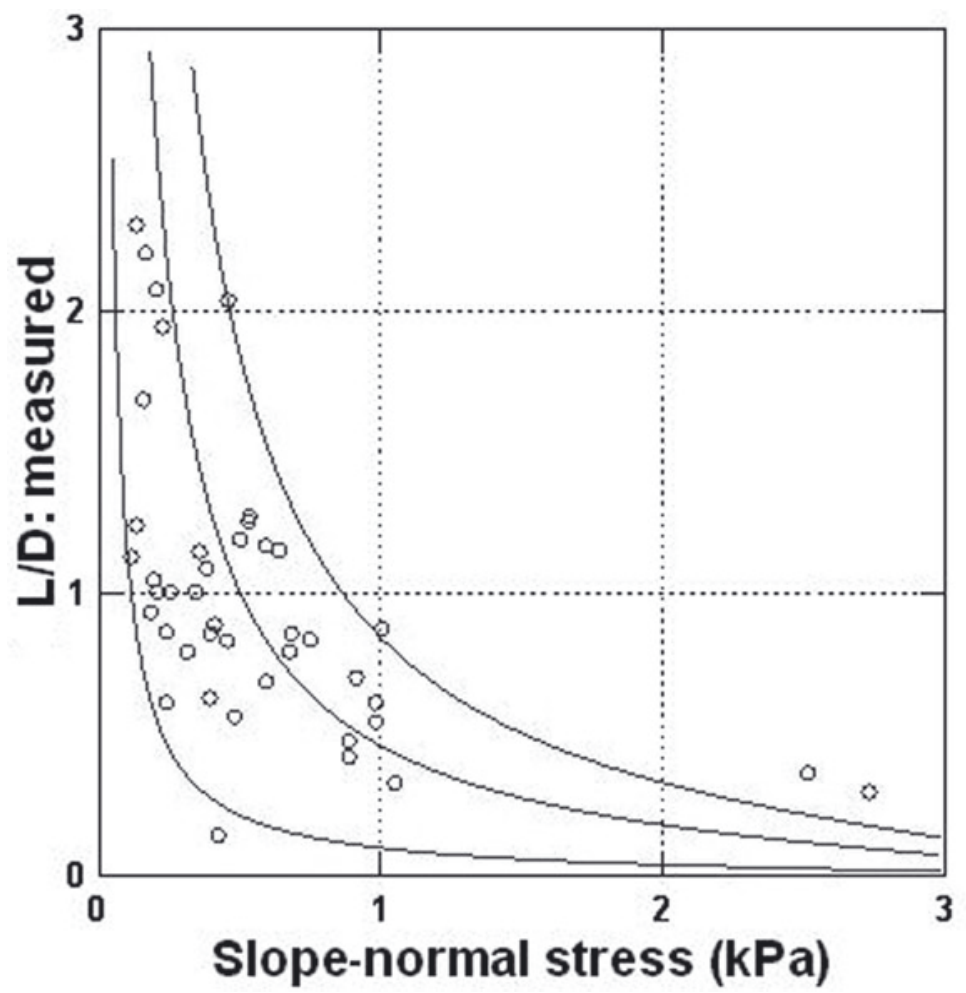

Fig. 6. Model limit estimates of $L / D$ from Equation (7) with $C_{2}=0.28 \mathrm{kPa}^{-1}$ and $C_{1}=115540992 \mathrm{~Pa}$ as minimum, median and maximum

of avalanche release. The reason is that mostly slope-normal weak-layer deformation is expected by slow snowfall loading for $\psi=0^{\circ}$, which apparently cannot drive a slopeparallel fracture. Slab avalanches under loading by snowfall are only observed under conditions for which slope-parallel deformation can become significant $\left(\psi>25^{\circ}\right)$. Thus, the link between the saw tests and natural fractures for $\psi=0^{\circ}$ (or low slope angles) is likely to be due to the presence of slopeparallel slip under complex loading due to the saw cut or human intervention.

The field data suggest that $L / D$ is in the range 0.1-2.2 for dry snow with median about 0.9 . Thus, the median approximately matches the prediction of Bažant and others (2003) that the ratio should be of order one or somewhat larger. In addition, the data agree with the prediction of McClung and Schweizer (1999) that the critical length should be a significant fraction of a meter. From Table 3, the median critical lengths for all the tests are $\sim 30 \mathrm{~cm}$, with variation from about 0.1 to $0.6 \mathrm{~m}$. It is not surprising to find such variations since, in reality, each weak layer and slab consists of snow with a different combination of crystal forms and size and physical characteristics. The minimum value of $L(0.07 \mathrm{~m})$ is close to the estimate of the FPZ size from tensile tests. Fracture propagation would not normally be expected for sizes less than the FPZ.

The suggestion of small (tens of $\mathrm{cm}$ ) but finite critical lengths has very important implications for forecasting and decision-making for backcountry travel in avalanche terrain. Such small regions under a slab would be nearly impossible to locate. Similarly, it would be virtually impossible to measure their properties. The practical use of the test (Gauthier, 2007; Gauthier and Jamieson, 2008) is best

Table 3. Median values of $L$ and $L / D$ (measured and calculated) for three layers at different locations. The test sequences are chosen for different slope angles to assess slope-normal dependence. Weak-layer forms are DF (decomposing and fragmented) and SH (surface hoar). The values of $L / D$ are calculated from Equation (4). The measured values represent the median of each test set. Cases in the top three rows are from Gauthier and Jamieson (2008) and the other cases are from the University of British Columbia

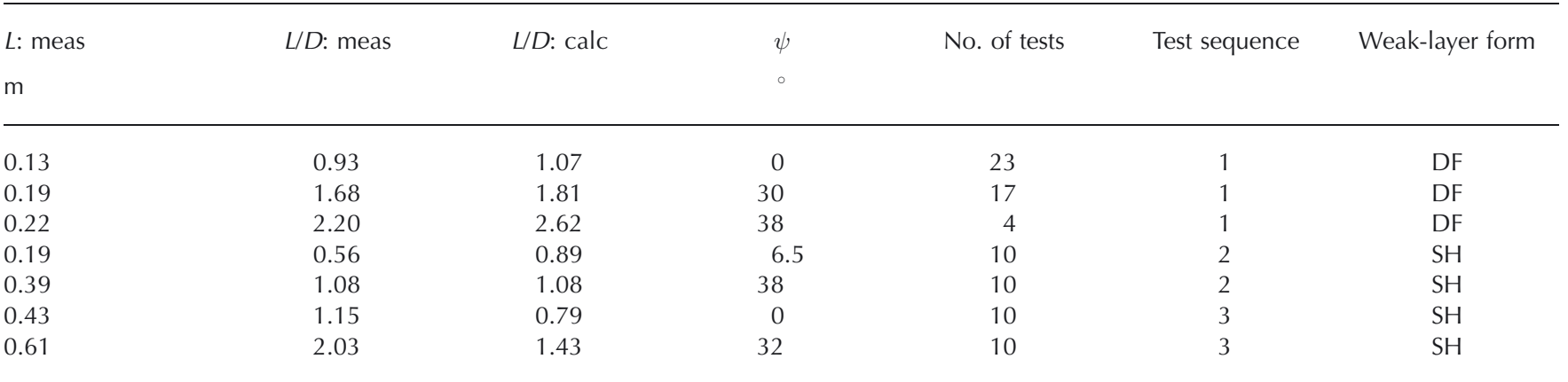


centred on how likely the fracture is to propagate for considerable distance and release an avalanche.

\section{SUMMARY AND LIMITATIONS}

Every slab/weak-layer combination has different mechanical properties. However, in this paper, the values of $\mu^{*}$ were varied with weak-layer type and the values of $E^{\prime}$ were varied with slab density $\rho$ while the other two parameters not measured in the tests $\left(\bar{\delta}, G_{\|}\right)$were taken constant. This deficiency limits the accuracy of the predictions and increases scatter (Fig. 3).

The model sometimes does not perform well at high normal stress (thick slabs). This can be due to a number of factors. The most likely is that the constant median value $G_{\| I}=0.02 \mathrm{~J} \mathrm{~m}^{-2}$ used in the evaluation may be too low since thicker slabs generally imply older snow in the weak layer which strengthens as it ages and overburden increases.

The propagation saw-test experiments display 2-D weaklayer deformation whereas the model here contains only 1-D deformation based on slope-parallel slip. Due to the applied normal load acting on the weak-layer plane and the slope-normal displacement, it is not possible that the conditions in a propagation saw test constitute pure mode II loading.

Measurements of the slope-normal displacement in the tests show that it implies closure of the gap created by the saw and mode I loading. It is possible that the energy implied by the interaction of slope-normal stress and slopenormal displacement does not have much influence on the conditions for slope-parallel propagation. For small-scale yielding, Broberg (1999) shows that for the case of a crack moving without change of direction and mixed mode I and II loading, the energy released by the action of slope-normal stress and slope-normal displacement does not produce energy together with slope-parallel slip. Primary slopeparallel propagation is observed in the tests from precision deformation measurements along with speed and acceleration calculations prior to dynamic slope-normal collapse. The slope-parallel propagation may represent the path of least energy needed to propagate fracture due to the low expected values of $G_{\| I}$ in the fragile weak layers tested (McClung, 2007c; Sigrist and Schweizer, 2007) and the imposition of slope-parallel slip by the saw action. From Equation (1), neglecting the pressure term gives a maximum value of slope-parallel slip $\delta_{0}=0.2 \mathrm{~mm}$ for $\mu^{*}=0.2$ (surface hoar) and the median value of $\sigma_{\mathrm{N}}=462 \mathrm{~Pa}$, but this is in the weak layer, not the slab.

The model used here contains the basic elements experimentally displayed by alpine snow: rate dependence, finite-sized fracture process zone, pressure sensitivity and strain-softening. One important result of this paper is to illustrate that a simple model can provide a reasonable match to field data using known snow properties. The simple model used requires at least five parameters which are not measured in the tests. A model based on LEFM requires fewer parameters but it would be inconsistent with the way snow deforms and fails. LEFM implies rate independence and infinitesimal FPZ.

Alpine snow is highly rate-dependent. For a density of $200 \mathrm{~kg} \mathrm{~m}^{-3}$, changes in modulus from a frequency of $1-100 \mathrm{~Hz}$ imply that $E^{\prime}$ (Mellor, 1975; Sigrist, 2006) increases by more than a factor of 10 or that values of $L / D$ increase by more than a factor of 3 . The analysis in this paper does not apply to applications such as high rate of energy delivery during explosive control since the test data were performed with a saw speed of $\sim 20 \mathrm{~cm} \mathrm{~s}^{-1}$.

No claim is made that the simple model used here (McClung, 2009b) is definitive in relation to avalanche fractures. However, it is consistent with the manner in which snow deforms, fails and fractures and it provides a reasonable match to the test data.

\section{ACKNOWLEDGEMENTS}

This research was sponsored by Canadian Mountain Holidays, the Natural Sciences and Engineering Research Council of Canada and the University of British Columbia. I am extremely grateful for all the support. E. Sharp assisted with the field measurements and C. Borstad also assisted with the field measurements and filming.

\section{REFERENCES}

Bažant, Z.P. 2005. Scaling of structural strength. Second edition. Amsterdam, Elsevier Butterworth-Heinemann.

Bažant, Z.P. and J. Planas. 1998. Fracture and size effect in concrete and other quasibrittle materials. Boca Raton, FL, CRC Press.

Bažant, Z.P., G. Zi and D.M. McClung. 2003. Size effect law and fracture mechanics of the triggering of dry slab snow avalanches. J. Geophys. Res., 108(B2), 2119. (10.1029/2002JB001884.)

Borstad, C.P. and D.M. McClung. 2009. Size effect in dry snow slab tensile fracture. In Proceedings of the 12th International Conference on Fracture, 12-17 July 2009, Ottawa, Canada. Ottawa, Ont., National Research Council of Canada.

Broberg, K.B. 1999. Cracks and fractures. San Diego, CA, Academic Press.

Camponovo, C. and J. Schweizer. 2001. Rheological measurements of the viscoelastic properties of snow. Ann. Glaciol., 32, 44-50.

Chae, Y.S. 1967. Frequency dependence of dynamic moduli of, and damping in snow. In Oura, H., ed. Physics of snow and ice. Sapporo, Hokkaido University. Institute of Low Temperature Science, 827-842.

Chalmers, T.S. and J.B. Jamieson. 2003. A snow-profile-based forecasting model for skier-triggered avalanches on surface hoar layers in the Columbia Mountains of Canada. Cold Reg. Sci. Technol., 37(3), 373-383.

Cleary, M.P. and J.R. Rice. 1974. Elementary models for the growth of slip-surfaces in progressive failure. Providence, RI, Brown University. Division of Engineering. (Report MRL-E91.)

Gauthier, D. 2007. A practical field test for propagation and arrest in weak snowpack layers in relation to slab avalanche release. (PhD thesis, University of Calgary.)

Gauthier, D. and J.B. Jamieson. 2008. Evaluation of a prototype field test for fracture and failure propagation in weak snow pack layers. Cold Reg. Sci. Technol., 51(2-3), 87-97.

Haefeli, R. 1951. Investigations and measurements of the shear strengths of saturated cohesive soils. Géotechnique, 2, 186-208.

Haefeli, R. 1954. Snow mechanics with references to soil mechanics. In Snow and its metamorphism. Wilamette, IL, US Army Corps of Engineers. Snow, Ice and Permafrost Research Establishment, 59-218. (SIPRE Transl. 14.)

Heierli, J., P. Gumbsch and M. Zaiser. 2008. Anticrack nucleation as triggering mechanism for snow slab avalanches. Science, 321(5886), 240-243.

Hull, D. and T.W. Clyne. 1996. An introduction to composite materials. Second edition. Cambridge, Cambridge University Press.

Hutchinson, J.W. and Z. Suo. 1992. Mixed mode cracking in layered materials. Adv. Appl. Mech., 29, 63-191.

Jamieson, J.B. 1995. Avalanche prediction for persistent snow slabs. (PhD thesis, University of Calgary.) 
McClung, D.M. 1977. Direct simple shear tests on snow and their relation to slab avalanche formation. J. Glaciol., 19(81), 101-109.

McClung, D.M. 1981. Fracture mechanical model of dry slab avalanche release. J. Geophys. Res., 86(B11), 10,783-10,790.

McClung, D.M. 1987. Mechanics of snow slab failure from a geotechnical perspective. IAHS Publ. 162 (Symposium at Davos 1986 - Avalanche Formation, Movement and Effects), 475-508.

McClung, D.M. 2007a. Dry snow slab shear fracture speeds. Geophys. Res. Lett., 34(10), L10502. (10.1029/2007GL029261.)

McClung, D.M. 2007b. Fracture energy applicable to dry snow slab avalanche release. Geophys. Res. Lett., 34(2), L02503. (10.1029/ 2006GL028238.)

McClung, D. 2007c. Fracture properties of faceted snow. Geophys. Res. Abstr., 9, EGU2007-A-03123.

McClung, D.M. 2009a. Dimensions of dry snow slab avalanches from field measurements. J. Geophys. Res., 114(F1), F01006. (10.1029/2007JF000941.)

McClung, D.M. 2009b. Dry snow slab quasi-brittle fracture initiation and verification from field tests. J. Geophys. Res., 114(F1), F01022. (10.1029/2007JF000913.)

McClung, D. and P. Schaerer. 2006. The avalanche handbook. Third edition. Seattle, WA, The Mountaineers.

McClung, D.M. and J. Schweizer. 1999. Skier triggering, snow temperatures and the stability index for dry-slab avalanche inititation. J. Glaciol., 45(150), 190-200.

Mellor, M. 1975. A review of basic snow mechanics. IAHS Publ. 114 (Symposium at Grindelwald 1974 - Snow Mechanics), 251-291.

Palmer, A.C. and J.R. Rice. 1973. The growth of slip surfaces in the progressive failure of over-consolidated clay. Proc. $R$. Soc. London, Ser. A, 332(1591), 527-548.
Perla, R.I. and E.R. LaChapelle. 1970. A theory of snow slab failure. J. Geophys. Res., 75(36), 7619-7627.

Rice, J.R. 1973. The initiation and growth of shear bands. In Palmer, A.C., ed. Symposium on the Role of Plasticity in Soil Mechanics, 13-15 September, 1973, Cambridge. Proceedings. Cambridge, University of Cambridge. Department of Engineering, 263-278.

Salm, B. 1977. Snow forces. J. Glaciol., 19(81), 67-100.

Schulson, E.M. and P. Duval. 2009. Creep and fracture of ice. Cambridge, etc., Cambridge University Press.

Schweizer, J. 1998. Laboratory experiments on shear failure of snow. Ann. Glaciol., 26, 97-102.

Schweizer, J., J.B. Jamieson and M. Schneebeli. 2003. Snow avalanche formation. Rev. Geophys., 41(4), 1016. (10.1029/ 2002RG000123.)

Shinojima, K. 1967. Study on the visco-elastic deformation of deposited snow. In Oura, H., ed. Physics of snow and ice. Sapporo, Hokkaido University. Institute of Low Temperature Science, 875-907.

Sigrist, C. 2006. Measurement of fracture mechanical properties of snow and application to dry snow slab avalanche release. (PhD thesis, Swiss Federal Institute of Technology.)

Sigrist, C. and J. Schweizer. 2007. Critical energy release rates of weak snowpack layers determined in field experiments. Geophys. Res. Lett., 34(3), L03502. (10.1029/2006GL028576.)

Sigrist, C., J. Schweizer, H. Schindler and J. Dual. 2005. On size and shape effects in snow fracture toughness measurements. Cold Reg. Sci. Technol., 43(1-2), 24-35.

Van Herwijnen, A. and J. Heierli. 2009. Measurement of crack-face friction in collapsed weak snow layers. Geophys. Res. Lett., 36(23), L23502. (10.1029/2009GL040389.)

Zeidler, A. and B. Jamieson. 2006. Refinements of empirical models to forecast shear strength of persistent weak layers: Part B: Layers of surface hoar crystals. Cold Reg. Sci. Technol., 44(3), 184-193. 